\title{
Attenuation of $\beta$-Amyloid-Induced Oxidative Cell Death by Sulforaphane via Activation of NF-E2-Related Factor 2
}

\author{
Chan Lee, ${ }^{1}$ Gyu Hwan Park, ${ }^{2}$ Seong-Ryong Lee, ${ }^{1}$ and Jung-Hee Jang ${ }^{1}$ \\ ${ }^{1}$ Department of Pharmacology, School of Medicine, Keimyung University, Daegu 704-701, Republic of Korea \\ ${ }^{2}$ Research Institute of Pharmaceutical Sciences, College of Pharmacy, Kyungpook National University, \\ Daegu 702-701, Republic of Korea \\ Correspondence should be addressed to Jung-Hee Jang; pamy202@kmu.ac.kr
}

Received 11 January 2013; Revised 19 May 2013; Accepted 22 May 2013

Academic Editor: Mi-Kyoung Kwak

Copyright (C) 2013 Chan Lee et al. This is an open access article distributed under the Creative Commons Attribution License, which permits unrestricted use, distribution, and reproduction in any medium, provided the original work is properly cited.

\begin{abstract}
$\beta$-amyloid peptide $(\mathrm{A} \beta)$, a major component of senile plaques, plays important roles in neuropathology of Alzheimer's disease (AD). An array of in vitro and in vivo data indicates that $\mathrm{A} \beta$-induced neuronal death is mediated by oxidative stress. In this study, we aimed to investigate effects of sulforaphane (SUL), an isothiocyanate in cruciferous vegetables, on $\mathrm{A} \beta$-induced oxidative cell death in SHSY5Y cells. Cells treated with $\mathrm{A} \beta_{25-35}$ exhibited decreased cell viability and underwent apoptosis as determined by MTT assay and TUNEL, respectively. $\mathrm{A} \beta_{25-35}$-induced cytotoxicity and apoptotic characteristics such as activation of c-JNK, dissipation of mitochondrial membrane potential, altered expression of $\mathrm{Bcl}-2$ family proteins, and DNA fragmentation were effectively attenuated by SUL pretreatment. The antiapoptotic activity of SUL seemed to be mediated by inhibition of intracellular accumulation of reactive oxygen species and oxidative damages. SUL exerted antioxidant potential by upregulating expression of antioxidant enzymes including $\gamma$-glutamylcysteine ligase, NAD(P)H:quinone oxidoreductase-1, and heme oxygenase-1 via activation of NF-E2-related factor 2(Nrf2). The protective effect of SUL against $\mathrm{A} \beta_{25-35}$-induced apoptotic cell death was abolished by siRNA of Nrf2. Taken together, the results suggest that pharmacologic activation of Nrf2 signaling pathway by SUL might be a practical prevention and/or protective treatment for the management of AD.
\end{abstract}

\section{Introduction}

Alzheimer's disease (AD) is one of the most common forms of senile dementia, characterized by progressive loss of memory and decline of cognitive functions due to neuronal death in the brain. There are two classical pathological hallmarks of $\mathrm{AD}$ [1]. One is extraneuronal accumulation of amyloid plaques composed of $\beta$-amyloid peptide $(\mathrm{A} \beta)$, which is produced by proteolytic cleavage from amyloid precursor protein (APP) with sequential actions of $\beta$ and $\gamma$-secretases. The other is intraneuronal deposits of neurofibrillatory tangles (NFT) consisting of hyperphosphorylated tau protein generated by actions of upstream kinases such as glycogen synthase kinase- $3 \beta$ (GSK-3 $\beta$ ) and cyclin-dependent kinase 5 (CDK5). Therefore, treatments for $\mathrm{AD}$ have been developed based on these two molecular approaches [2]. A $\beta$-based therapies include utilizing $\beta$ - or $\gamma$-secretases inhibitors, $A \beta$ aggregation blockers, and $\mathrm{A} \beta$ catabolism inducers. Tau-based therapies make an advantage of upstream kinase inhibitors, microtubule stabilizers, and tau catabolism inducers.

However, pathogenesis of $\mathrm{AD}$ appears to be multifactorial events, whereby genetic as well as environmental factors, oxidative stress, depletion of endogenous antioxidants, altered ion levels, inflammation, disruption in neurotransmission, synaptic dysfunction, and neuronal cell death operate sequentially or in parallel [3]. Among them we have focused on $\mathrm{A} \beta$-induced oxidative damages and neuronal cell death as one of the major causes of $\mathrm{AD}$ pathology. Oxidative stress has been proposed to be an important factor in the development and progression of $\mathrm{AD}$ and contributes to $A \beta$ aggregation and NTF formation as well [4]. Reactive oxygen species (ROS) can be derived from diverse cellular sources, among which are enzymatic reactions, mitochondrial deterioration, and imbalance in redox transition metal ions. The excessive production and accumulation of ROS by 
$\mathrm{A} \beta$ can cause functional and structural changes in critical macromolecules leading to lipid peroxidation, protein oxidation, and DNA cleavage and altered signal transduction [5]. The levels of molecular markers for lipid peroxidation (HNE, isoprostanes, etc.) and oxidation of proteins (carbonyls) and DNAs (8-OHdG) are reported to be elevated in the brains or cerebrospinal fluid of patients with $\mathrm{AD}[6]$.

Given the involvement of $\mathrm{A} \beta$-induced oxidative stress in the etiology and pathology of $\mathrm{AD}$, one of the promising approaches to preventive interventions for $\mathrm{AD}$ includes antioxidant therapy by inhibiting the detrimental effects of excess ROS through induction of endogenous antioxidant enzymes. Particularly, many studies highlighted natural phytochemicals derived from medicinal herbs and foods as potential candidates which can protect neurons against various toxic compounds and exert beneficial effects on neuronal cells $[7,8]$. Sulforaphane (4-methylsulfinylbutyl isothiocyanate, SUL) is a naturally occurring isothiocyanate present in cruciferous vegetables, such as broccoli, cabbage, and cauliflower and has been shown to exhibit anticarcinogenic, anti-inflammatory, antioxidant, chemopreventive, and cytoprotective properties $[9,10]$. Recently, it has been reported that SUL can penetrate blood brain barrier and exert neuroprotective effects in diverse in vitro cell culture and in vivo animal models of neurological disorders [11, 12]. SUL has been reported to attenuate microglia-induced inflammation in hippocampus of LPS-treated mice and BV-2 microglia cells [13]. In addition, SUL protected against oxidative stress induced by hypoxia-ischemic injury [14], oxygen and glucose deprivation [15], 6-hydroxydopamine (6-OHDA) [16], superoxide [17], hydrogen peroxide $\left(\mathrm{H}_{2} \mathrm{O}_{2}\right)$, and glutamate [18]. However, there has been no direct evidence demonstrating that the protective effect of SUL against $A \beta$-induced oxidative damage and cell death as yet.

Therefore, in this study we examined whether SUL can suppress $A \beta_{25-35}$-induced oxidative damage and cell death in human neuroblastoma SH-SY5Y cells via augmentation of antioxidant defense capacity by activation of NF-E2-related factor 2 (Nrf2) and the subsequent expression of antioxidant and phase II detoxification enzymes which play key roles in inhibiting ROS production and oxidative damages.

\section{Materials and Methods}

2.1. Chemicals and Reagents. $\mathrm{A} \beta_{25-35}$ and SUL were purchased from American Peptide (Sunnyvale, CA, USA) and LKT Laboratories, Inc. (St. Paul, MN, USA), respectively. Dulbecco's modified Eagle's medium (DMEM), fetal bovine serum (FBS), and penicillin-streptomycin antibiotic were supplied from Gibco BRL (Grand Island, NY, USA). Tetramethylrhodamine ethyl ester (TMRE) and $2^{\prime} 7^{\prime}$ dichlorofluorescein diacetate (DCF-DA) dyes were the products of Invitrogen Co. (Carlsbad, CA, USA). Anti-phospho-JNK (p-JNK), anti-JNK, anti-Bcl-2, anti-Bax, anti$\gamma$-glutamylcysteine ligase (GCL), anti-NAD(P)H:quinone oxidoreductase-1 (NQO-1), and anti-Nrf2 antibodies were obtained from Santa Cruz Biotechnology, Inc (Santa Cruz, CA, USA). Anti-heme oxygenase-1 (HO-1) antibody was provided by Stressgen (Ann Arbor, MI, USA). Anti-4hydroxynonenal (4-HNE) and anti-phospho-Nrf2 antibodies were supplied from Abcam (Cambridge, MA, USA) and Epitomics, Inc. (Burlingame, CA, USA), respectively. MTT [3-(4,5-dimethylthiazol-2-yl)-2,5 diphenyltetrazolium bromide], anti-actin antibody, and other chemical reagents were purchased from Sigma-Aldrich (St. Louis, MO, USA).

2.2. SH-SY5Y Cell Culture. SH-SY5Y cells were maintained in DMEM media containing 10\% FBS, penicillin (10000 U), and streptomycin $(100 \mu \mathrm{g} / \mathrm{mL})$ in a $5 \% \mathrm{CO}_{2}$ incubator at $37^{\circ} \mathrm{C}$ under a humidified atmosphere. The media were changed every other day. Cells were seeded at an appropriate density according to the each experimental scale.

2.3. Cell Viability Assay (MTT Dye Reduction Assay). Cytotoxicity was determined by the conventional MTT dye reduction assay. Cells were seeded in 48-well plate at a density of $5 \times 10^{4}$ cells/well and incubated with $\mathrm{A} \beta_{25-35}(15 \mu \mathrm{M})$ for $24 \mathrm{~h}$ with or without $30 \mathrm{~min}$ pretreatment of SUL $(1,2$, and $5 \mu \mathrm{M})$ or $N$-acetylcysteine (NAC, 0.5 and $1 \mathrm{mM}$ ). After treatment, MTT solution $(5 \mathrm{mg} / \mathrm{mL})$ was added and further incubated for $2 \mathrm{~h}$ at $37^{\circ} \mathrm{C}$. The formazan crystals formed in viable cells were extracted with $200 \mu \mathrm{L}$ of dimethylsulfoxide (DMSO) and the absorbance was measured in a microplate reader at $570 \mathrm{~nm}$ (Emax, Molecular Device, CA, USA). Relative cytotoxicity was calculated as percentage of viable cells with respect to the optical density (OD) value of the living cells in the control as $100 \%$.

2.4. Measurement of DNA Fragmentation (TUNEL). For detection of DNA fragmentation, terminal deoxynucleotidyl transferase-mediated dUTP nick end labeling (TUNEL) (Roche diagnostics GmbH, Mannheim, Germany) was performed in SH-SY5Y cells $\left(8 \times 10^{4}\right.$ cells $/ 500 \mu \mathrm{L}$ in 4 -well chamber slide) exposed to $15 \mu \mathrm{M} \mathrm{A} \beta_{25-35}$ for $24 \mathrm{~h}$ in the presence or absence of SUL or NAC pretreatment. The slide was rinsed with phosphate-buffered saline (PBS) three times and fixed in $10 \%$ neutral buffered formalin solution for $30 \mathrm{~min}$ at room temperature (RT). After incubation with $0.3 \% \mathrm{H}_{2} \mathrm{O}_{2}$ in methanol for $30 \mathrm{~min}$ at RT to inactivate endogenous peroxidase, the slide was further reacted with a permeabilizing solution $(0.1 \%$ sodium citrate and $0.1 \%$ Triton X-100) for $2 \mathrm{~min}$ at $4^{\circ} \mathrm{C}$. The cells were treated with TUNEL reaction mixture for $1 \mathrm{~h}$ at $37^{\circ} \mathrm{C}$ and then labeled with antidigoxigenin peroxidase for additional $30 \mathrm{~min}$ at $37^{\circ} \mathrm{C}$. After rinsing with PBS three times, color development was performed with 3,3' -diaminobenzidine (Vector Laboratories, CA, USA). The stained images were examined under a light microscope (Leica Microsystems, Wetzlar, Germany).

2.5. Western Bolt Analysis. Cells extracts were prepared by washing cells with PBS and centrifugation at 7,000 g for $5 \mathrm{~min}$. The collected cells were lysed with RIPA buffer (Pierce Biotechnology, Inc., Rockford, IL, USA) and protease inhibitor cocktail tablet (Roche Diagnostics) on ice for $30 \mathrm{~min}$. Protein concentration was quantified by BCA Protein Assay (Pierce Biotechnology). Protein samples were boiled in 
SDS sample buffer and separated on SDS-PAGE using 10\%$12 \%$ acrylamide gels. Subsequently, protein samples were transferred onto polyvinylidene fluoride (PVDF, Roche Diagnostics) membranes by transblot electrophoretic transfer for $3 \mathrm{~h}$ at a constant current of $300 \mathrm{~mA}$. The nonspecific binding of antibodies was blocked using 5\% (w/v) nonfat milk in PBS containing 0.1\% Tween-20 (PBST) for $1 \mathrm{~h}$ at RT. After blocking, the membranes were probed with the primary antibodies overnight at $4^{\circ} \mathrm{C}$. The membranes were washed in PBST three times for $10 \mathrm{~min}$ each. The corresponding secondary antibodies were diluted in PBST and reacted with the membranes for $1 \mathrm{~h}$ at RT. Finally, immunoreactive bands were visualized by chemiluminescence method (Pierce Biotechnology). The images and relative density of immunoreactive bands were analyzed by using ImageQuant LAS 4000 Multi-Gauge software (Fujifilm, Tokyo, Japan).

2.6. Measurement of Mitochondrial Membrane Potential $(M M P)$. For detection of mitochondrial transmembrane potential in SH-SY5Y cells, TMRE probe was utilized. The cells were seeded at a density of $8 \times 10^{4}$ cells $/ 500 \mu \mathrm{L}$ in 4 -well chamber slide and treated with $15 \mu \mathrm{M} \mathrm{A} \beta_{25-35}$ for $24 \mathrm{~h}$ in the absence or presence of SUL or NAC. After treatment, cells were washed with PBS and further incubated with TMRE solution (50 $\mu \mathrm{M}$ in PBS) for $15 \mathrm{~min}$ at $37^{\circ} \mathrm{C}$. The fluorescence images were recorded and quantified by using a fluorescence microscope (Leica Microsystems) with excitation at $540 \mathrm{~nm}$ and emission at $590 \mathrm{~nm}$.

2.7. Measurement of Intracellular ROS Accumulation. To monitor the intracellular accumulation of ROS, the fluorescent probe DCF-DA was used. After treatment of $\mathrm{SH}-$ SY5Y cells $\left(8 \times 10^{4}\right.$ cells $/ 500 \mu \mathrm{L}$ in 4 -well chamber slide $)$ with $\mathrm{A} \beta_{25-35}(15 \mu \mathrm{M})$ in the presence or absence of SUL for $6 \mathrm{~h}$, cells were incubated with DCF-DA solution ( $50 \mu \mathrm{M}$ in PBS) at $37^{\circ} \mathrm{C}$ for $15 \mathrm{~min}$. The fluorescence signals inside cells were excited at $488 \mathrm{~nm}$ and emission was monitored at $535 \mathrm{~nm}$. The images were recorded with a fluorescence microscope (Leica Microsystems).

2.8. Protein Oxidation. The levels of protein carbonyls were determined by using OxyBlot Protein Oxidation Detection Kit (Millipore, MA, USA) according to the manufacturer's instruction. Briefly, the protein samples $(15 \mu \mathrm{g})$ were denatured by SDS ( $6 \%$ final concentration) and then derivatized to 2,4-dinitrophenylhydrazone (DNP-hydrazone) by incubation with 2,4-dinitrophenylhydrazine (DNPH) for $15 \mathrm{~min}$ at RT. After adding neutralization solution, the samples were electrophoresed on a 10\% SDS-PAGE gel and transferred to PVDF membrane. The membrane was incubated with blocking buffer for $1 \mathrm{~h}$ to reduce nonspecific binding and then reacted with anti-DNP primary antibody for $1 \mathrm{~h}$ at RT. After two times washing with PBST, the membrane was further incubated with HRP-conjugated secondary anti-rabbit antibody for $1 \mathrm{~h}$ at RT. The carbonylation bands were detected by using chemiluminescence method (Pierce Biotechnology).
2.9. Nuclear Protein Extraction. Nuclear protein extracts were prepared by using the Nuclear Extraction Kit (Chemicon, Inc., MA, USA). After treatment, SH-SY5Y cells were washed with ice cold PBS and harvested by centrifugation. The harvested cells were resuspended in ice-cold cytoplasmic lysis buffer, incubated on ice for $15 \mathrm{~min}$, and centrifuged at $8,000 \mathrm{~g}$ for $20 \mathrm{~min}$ at $4^{\circ} \mathrm{C}$. The pellet was resuspended in icecold nuclear extraction buffer, incubated on ice for $60 \mathrm{~min}$ using shaker, and centrifuged at $16,000 \mathrm{~g}$ for $7 \mathrm{~min}$ at $4^{\circ} \mathrm{C}$. The supernatant containing nuclear proteins were stored at $-80^{\circ} \mathrm{C}$ for western blot analysis and electrophoretic mobility shift assay (EMSA). Protein concentrations were determined by Bradford assay (BIO-RAD, CA, USA).

2.10. Electrophoretic Mobility Shift Assay (EMSA). The DNA binding activity of Nrf2 to antioxidant response element (ARE) was assessed by LightShift Chemiluminescent EMSA kit according to the procedure provided from Pierce Biotechnology. The isolated nuclear protein samples were combined with binding mixture $(1 \mu \mathrm{g}$ poly $(\mathrm{dI} \cdot \mathrm{dC}), 50 \%$ glycerol, $1 \%$ NP-40, $1 \mathrm{M} \mathrm{KCl}, 100 \mathrm{mM} \mathrm{MgCl}_{2}$, and $200 \mathrm{mM}$ EDTA (Pierce Biotechnology)) and incubated on ice for $20 \mathrm{~min}$. Subsequently, biotin-labeled oligonucleotide specific to $\operatorname{Nrf} 2\left(5^{\prime}\right.$ TGGGGAaCCTGTGCTGAGTCACTGGAG-3', Panomics, CA, USA) was added to the reaction mixture and additionally incubated for $10 \mathrm{~min}$ at RT. The DNA-protein complexes were separated on the $6 \%$ nondenaturing polyacrylamide gel at $80 \mathrm{~V}$ for $1 \mathrm{~h}$ and then transferred to nylon membrane (Pall Co., MI, USA) at $380 \mathrm{~mA}$ for $45 \mathrm{~min}$. The membrane was subjected to immediate cross-linking by transilluminator at $312 \mathrm{~nm}$ for $10 \mathrm{~min}$. After blocking the membrane with blocking buffer for $15 \mathrm{~min}$ at RT, the membrane was incubated with stabilized streptavidin-HRP for $15 \mathrm{~min}$ at RT. After three times washing with wash buffer, the DNA-protein complex bands were detected by chemiluminescence method (Pierce Biotechnology).

2.11. Synthetic Small Interfering RNA (siRNA) Transfection. For the knockdown experiments of Nrf2, SH-SY5Y cells were transiently transfected with siRNA of Nrf2 (Nrf2-siRNA) using DOTAP transfection reagent (Roche Diagnostics $\mathrm{GmbH}$ ) in accordance with the manufacturer's protocol. The sequences of the sense and antisense strands of the human Nrf2-siRNA were as follows: $5^{\prime}$-AAG AGU AUG AGC UGG AAA AAC TT-3' (sense) and $5^{\prime}$-GUU UUU CCA GCU CAU ACU CUU TT'- ${ }^{\prime}$ (antisense) which were selected by siRNA Target Finder software provided by Invitrogen. After transfection of SH-SY5Y cells with Nrf2siRNA, cells were further exposed to $\mathrm{A} \beta_{25-35}(15 \mu \mathrm{M})$ for $24 \mathrm{~h}$ in the presence or absence of SUL $(5 \mu \mathrm{M})$ pretreatment and then cell viability and molecular markers for apoptotic cell death were examined.

2.12. Statistical Analysis. SPSS software 13.0 (SPSS, Inc, Chicago, IL, USA) was used for the statistical analysis. All data represent at least three independent experiments and are expressed as mean \pm SD. Statistical comparisons between groups were made by one-way analysis of variance (ANOVA) 


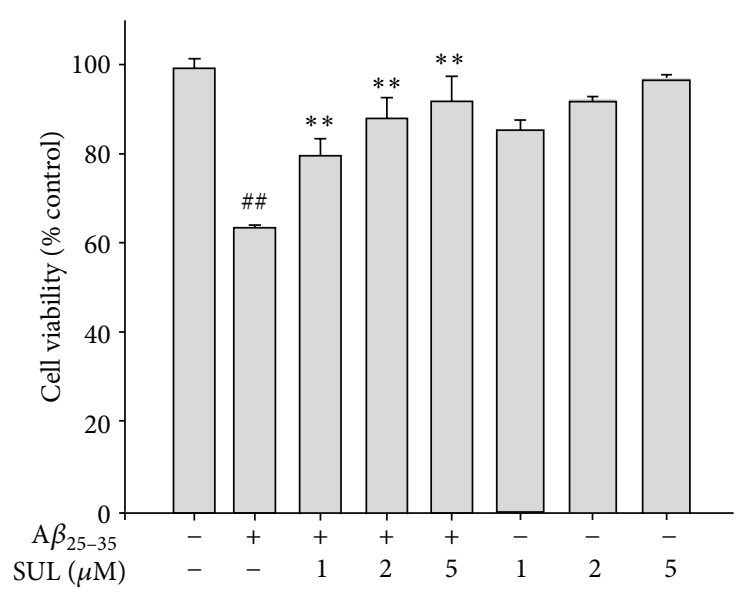

(a)

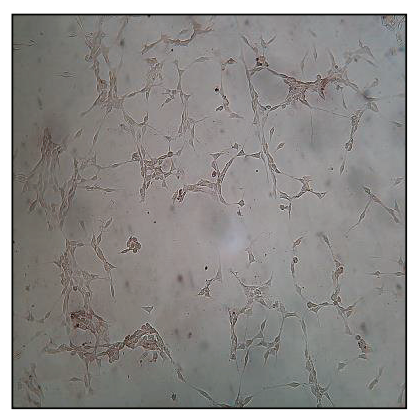

(A)

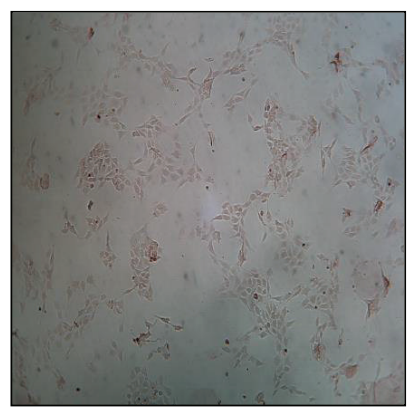

(C)

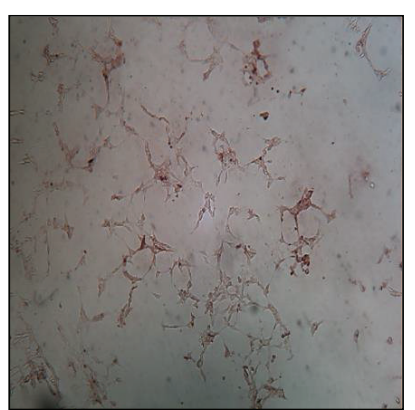

(B)

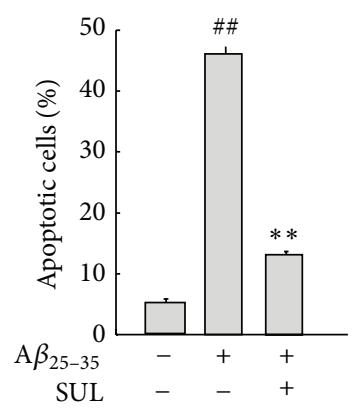

(D)

(b)

FIGURE 1: Protective effect of sulforaphane (SUL) on $\mathrm{A} \beta_{25-35}$-induced cytotoxicity and apoptotic cell death. SH-SY5Y cells were incubated with $15 \mu \mathrm{M} \mathrm{A} \beta_{25-35}$ with or without SUL $(1 \mu \mathrm{M}, 2 \mu \mathrm{M}$, and $5 \mu \mathrm{M})$ for $24 \mathrm{~h}$. (a) Viable cells were determined by MTT dye reduction assay. Cell viability is expressed as the percentage of control. Data are represented as mean \pm S.D. $(n=3) .{ }^{\# \#} P<0.01$, control versus $\mathrm{A} \beta_{25-35}$ and ${ }^{* *} P<$ 0.01, $\mathrm{A} \beta_{25-35}$ versus $\mathrm{A} \beta_{25-35}+$ SUL. (b) DNA fragmentation was measured by TUNEL. (A) Vehicle-treated control; (B) $\mathrm{A} \beta_{25-35}$ alone (15 $\mu \mathrm{M}$ ); (C) $\mathrm{A} \beta_{25-35}(15 \mu \mathrm{M})+\mathrm{SUL}(5 \mu \mathrm{M})$; (D) quantification of apoptotic cell death (\%).

followed by Tukey's test as post hoc analysis to determine individual group differences. Statistical significance was accepted at value of $P$ less than 0.05 .

\section{Results}

3.1. Protective Effect of SUL against $A \beta_{25-35}$-Induced Cytotoxicity and Apoptotic Cell Death. We have investigated the effect of SUL on $\mathrm{A} \beta_{25-35}$-induced cytotoxicity and apoptotic cell death in SH-SY5Y cells by MTT dye reduction assay and TUNEL staining, respectively. Cells were incubated with various concentrations of SUL $(1 \mu \mathrm{M}, 2 \mu \mathrm{M}$, and $5 \mu \mathrm{M}$ ) for $30 \mathrm{~min}$ followed by $15 \mu \mathrm{M} \mathrm{A} \beta_{25-35}$ treatment for additional $24 \mathrm{~h}$. Pretreatment of SUL protected against $\mathrm{A} \beta_{25-35}$-induced cytotoxicity in a concentration-dependent manner (Figure 1(a)). SUL-treated cells exhibited significantly higher cell viability than $\mathrm{A} \beta_{25-35}$-treated group did. In addition, $\mathrm{A} \beta_{25-35}$-induced apoptotic cell death was effectively suppressed by the pretreatment with SUL as assessed by TUNEL, which detects DNA fragmentation in situ, a typical marker for apoptosis (Figure 1(b)). SUL significantly reduced the number of TUNEL-positive cells caused by $\mathrm{A} \beta_{25-35}$ treatment.

We also confirmed the protective effect of SUL against $\mathrm{A} \beta_{25-35}$-induced apoptotic cell death by examining pro- or antiapoptotic signals, such as activation of JNK, expression of Bcl-2 family proteins, and dissipation of mitochondrial membrane potential (MMP). $A \beta_{25-35}$-induced apoptosis of SH-SY5Y cells was accompanied by activation of JNK via phosphorylation (Figure 2(a)) and a decreased $\mathrm{Bcl}-2$ as well as an increased Bax protein levels (Figure 2(b)). However, pretreatment of SUL dramatically reduced $\mathrm{A} \beta_{25-35^{-}}$ elevated phosphorylation of JNK and expression of proapoptotic protein Bax. Moreover, anti-apoptotic protein Bcl2 levels were effectively upregulated by SUL pretreatment. $\mathrm{A} \beta_{25-35}$ treatment also led to disruption of MMP as assessed by using TMRE cationic probe, which was shown as low fluorescence intensity compared with control group (Figure 2(c)). However, SUL pretreatment effectively restored $\mathrm{A} \beta_{25-35^{-}}$ decreased TMRE fluorescence intensity up to control levels representing recovery from the dissipation of MMP.

3.2. Inhibitory Effect of SUL on $A \beta_{25-35}$-Induced ROS Production and Subsequent Oxidative Damages. It has been reported that $\mathrm{A} \beta_{25-35}$-induced cytotoxicity and apoptotic cell death are mediated by oxidative stress. In another experiment, $\mathrm{A} \beta_{25-35^{-}}$ induced cytotoxicity (Figure 3(a)) and apoptotic cell death such as DNA fragmentation (Figure 3(b)) and impairment of MMP (Figure 3(c)) were effectively suppressed by pretreatment with NAC (0.5 mM and $1 \mathrm{mM})$, a glutathione (GSH) precursor with strong antioxidant activity. Based on the involvement of oxidative stress in $\mathrm{A} \beta_{25-35}$-induced apoptosis 


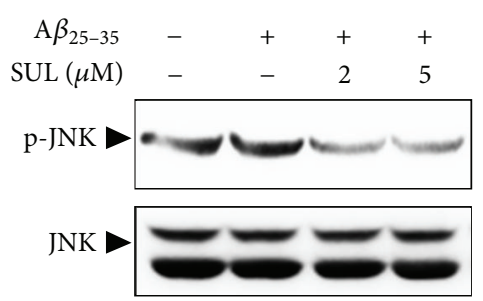

(a)

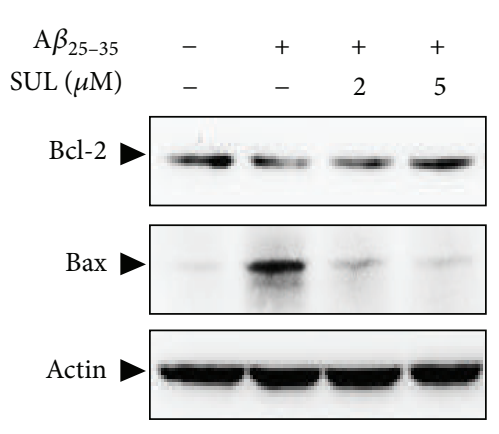

(b)

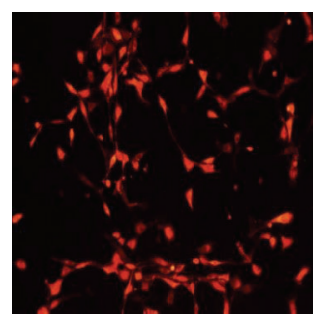

(A)
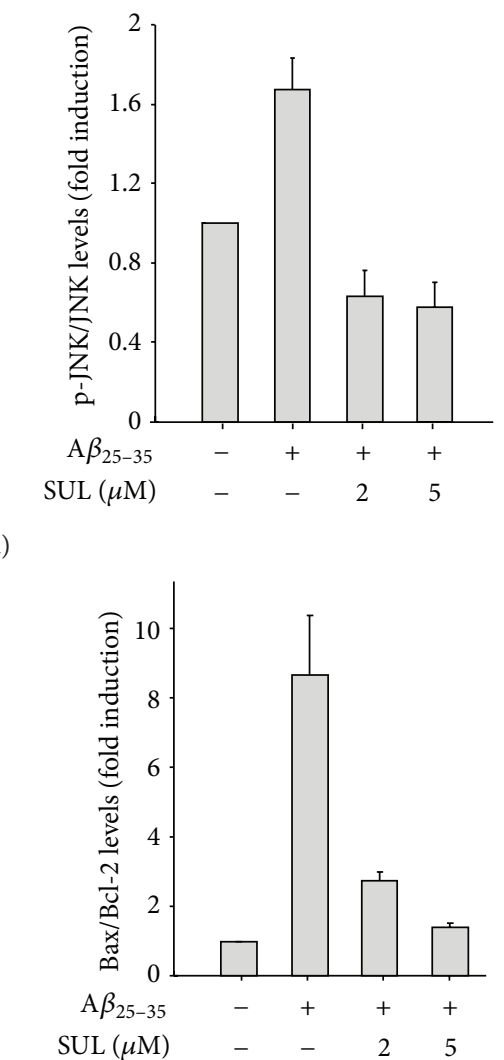

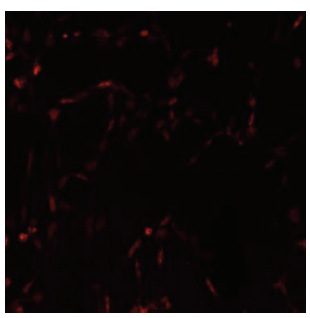

(B)

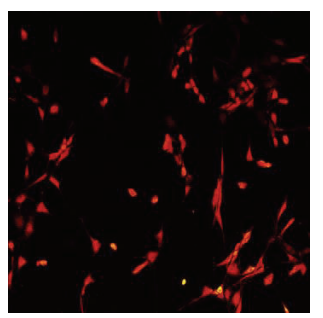

(C)

(c)

FIGURE 2: Protective effect of SUL on A $\beta_{25-35}$-induced pro-apoptotic signals. SH-SY5Y cells were exposed to $15 \mu \mathrm{M}$ of A $\beta_{25-35}$ in the presence or absence of SUL $(2 \mu \mathrm{M}$ and $5 \mu \mathrm{M})$ for $24 \mathrm{~h}$. Activation of JNK (a) and expression of Bcl-2 family proteins (b) were assessed by western blot analysis using anti-phospho-JNK, anti-JNK, anti-Bcl-2, anti-Bax, and anti-actin antibodies. Actin levels were monitored to verify equal amount of protein loading. Relative expression levels of $\mathrm{p}-\mathrm{JNK} / \mathrm{JNK}$ and $\mathrm{Bax} / \mathrm{Bcl}-2$ were quantified from three independent experiments and are represented on the right panels. (c) Mitochondria membrane potential was measured by immunofluorescence staining using TMRE probe. The representative images of TMRE fluorescence were shown. (A) Vehicle-treated control; (B) $\mathrm{A} \beta_{25-35}$ alone (15 $\left.\mu \mathrm{M}\right)$; (C) $\mathrm{A} \beta_{25-35}$ (15 $\left.\mu \mathrm{M}\right)+$ SUL $(5 \mu \mathrm{M})$.

in SH-SY5Y cells, in the next experiment we have examined the effect of SUL on $A \beta_{25-35}$-induced ROS formation. Cells were pretreated with SUL for $30 \mathrm{~min}$ before incubation with $\mathrm{A} \beta_{25-35}(15 \mu \mathrm{M})$ for additional $6 \mathrm{~h}$. $\mathrm{A} \beta_{25-35}$ treatment led to intracellular accumulation of ROS, which was attenuated by SUL pretreatment (Figure 4(a)) as assessed by relative fluorescence intensity of DCF-DA dye. The results indicated that SUL could inhibit $\mathrm{A} \beta_{25-35}$-induced ROS production in SH-SY5Y cells.
It is well known that ROS can cause oxidative stress to critical cellular macromolecules such as DNA, protein, and lipids. In the present study, treatment of $\mathrm{A} \beta_{25-35}(15 \mu \mathrm{M})$ caused oxidative damages to lipids (Figure 4(b)) and proteins in SH-SY5Y cells (Figure 4(c)), which were measured by formation of 4-HNE and protein carbonyls, respectively. 4-HNE and protein carbonyls are indicators of oxidative stress and key markers for oxidation of lipid and protein. $\mathrm{A} \beta_{25-35}$-induced lipid peroxidation (Figure 4(b)) and protein 


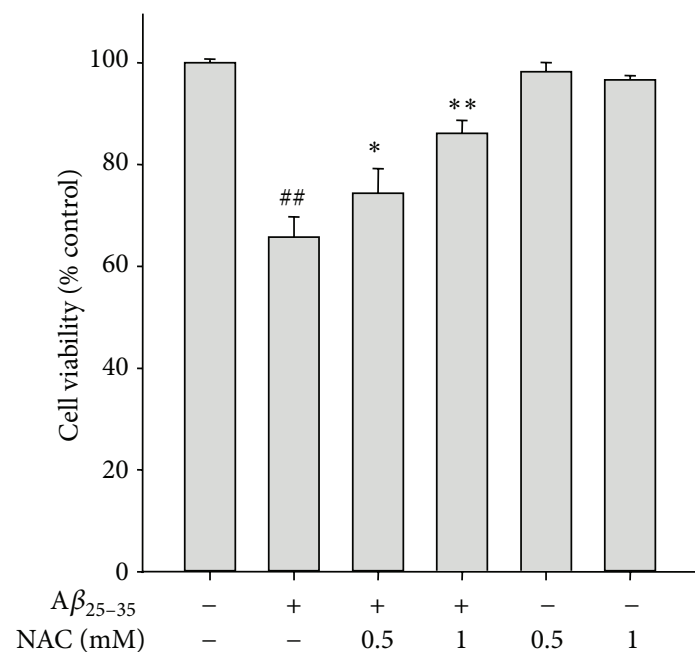

(a)

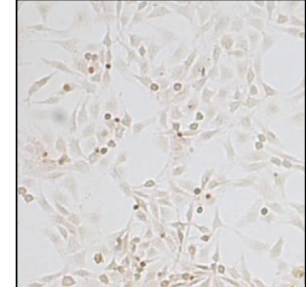

(A)

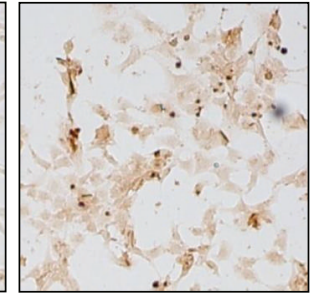

(B)

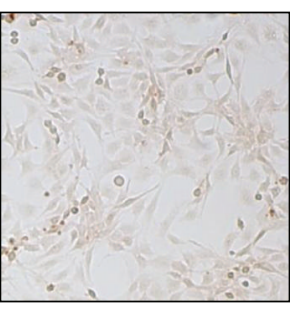

(C)

(b)

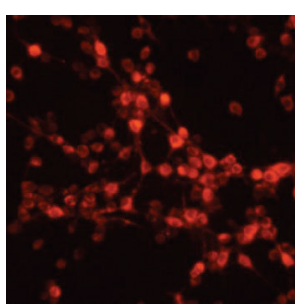

(A)

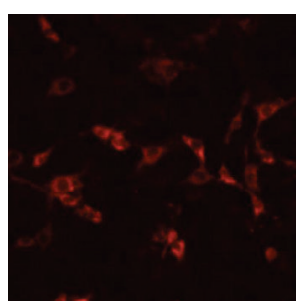

(B)

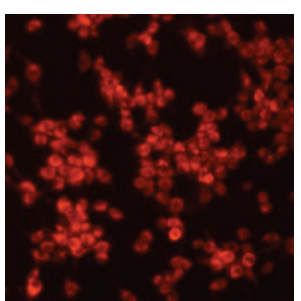

(C)

(c)

FIGURE 3: Protective effect of NAC on A $\beta_{25-35}$-induced apoptotic cell death. SH-SY5Y cells were treated with A $\beta_{25-35}(15 \mu \mathrm{M})$ with or without NAC $(0.5 \mathrm{mM}$ and $1 \mathrm{mM})$ for $24 \mathrm{~h}$. (a) Cell viability was measured and calculated by MTT dye reduction assay. Data are shown as mean \pm S.D. $(n=3) .{ }^{\# \#} P<0.01$, control versus $\mathrm{A} \beta_{25-35}$ and ${ }^{*} P<0.05$ or ${ }^{* *} P<0.01, \mathrm{~A} \beta_{25-35}$ versus $\mathrm{A} \beta_{25-35}+\mathrm{NAC}$. (b) Apoptotic cell death was examined by TUNEL staining. (A) Vehicle-treated control; (B) $\mathrm{A} \beta_{25-35}$ alone $(15 \mu \mathrm{M}) ;(\mathrm{C}) \mathrm{A} \beta_{25-35}(15 \mu \mathrm{M})+\mathrm{NAC}(1 \mathrm{mM})$. (c) MMP was monitored by relative TMRE fluorescence intensity. (A) Vehicle-treated control; (B) $\mathrm{A} \beta_{25-35}$ alone (15 $\left.\mu \mathrm{M}\right)$; (C) $\mathrm{A} \beta_{25-35}(15 \mu \mathrm{M})+\mathrm{NAC}(1 \mathrm{mM})$.

oxidation (Figure 4(c)) were substantially reduced by pretreatment of these cells with SUL.

\subsection{Augmentation of Cellular Antioxidant Defense Capacity by} SUL via Activation of Nrf2. To investigate molecular mechanisms of neuroprotection exerted by SUL against $\mathrm{A} \beta_{25-35^{-}}$ induced oxidative cell death, we have assessed expression levels of cellular antioxidant enzymes such as GCS, NQO1 , and HO-1. SH-SY5Y cells were treated with $5 \mu \mathrm{M}$ SUL for the indicated time periods, and protein levels of GCS, NQO1 , and $\mathrm{HO}-1$ were determined by western blot analysis using specific antibodies. As shown in Figure 4(d), the expression of GCS and NQO-1 was increased by SUL treatment in a timedependent manner which peaked at $24 \mathrm{~h}$. In addition, HO1 protein levels increased from $3 \mathrm{~h}$ after SUL treatment and were maintained up to $12 \mathrm{~h}$ (Figure $4(\mathrm{~d})$ ). All these results indicated that SUL could induce the expression of antioxidant enzymes to protect cells from oxidative damages caused by $\mathrm{A} \beta_{25-35}$ in SH-SY5Y cells.

To elucidate upstream regulator for the SUL-induced upregulation of the antioxidant enzymes, we have focused on the activation of redox-sensitive transcription factor Nrf2.
When SH-SY5Y cells were treated with $5 \mu \mathrm{M}$ SUL for the indicated times, nuclear translocation (Figure 5(a)), ARE-DNA binding (Figure 5(b)), and phosphorylation (Figure 5(c)) of Nrf2 were assessed by western blot analysis and EMSA. Treatment of SH-SY5Y cells with SUL increased nuclear levels of Nrf2 (Figure 5(a)) and Nrf2 binding to ARE promoter sequence (Figure 5(b)) with similar kinetic patterns. Moreover, SUL treatment increased phosphorylation of Nrf2 at Ser-40 residue as well (Figure 5(c)), which is known to facilitate the dissociation of Nrf2 from Keapl rendering its translocation to nucleus.

To further verify the direct role of Nrf2 in mediating the cytoprotective effect of SUL against $\mathrm{A} \beta_{25-35}$-induced oxidative cell death, we have downregulated the Nrf2 expression by transient transfection of SH-SY5Y cells with Nrf2-siRNA. The cellular protection of SUL on $\mathrm{A} \beta_{25-35}$-induced cytotoxicity (Figure 6(a)) and DNA fragmentation (Figure 6(b)) were abolished by knockdown of Nrf2 gene with Nrf2-siRNA. Moreover, the protective effect of SUL on $\mathrm{A} \beta_{25-35}$-mediated proapoptotic signals such as decreased MMP (Figure 6(c)) and increased $\mathrm{Bax} / \mathrm{Bcl}-2$ ratio (Figure $6(\mathrm{~d})$ ) and subsequent oxidative damages to lipids determined by 4-HNE formation (data not shown) were substantially abrogated by Nrf-siRNA 


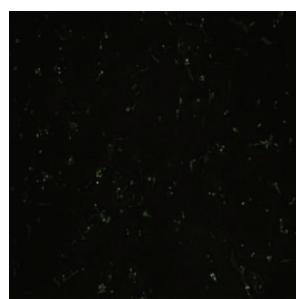

(A)

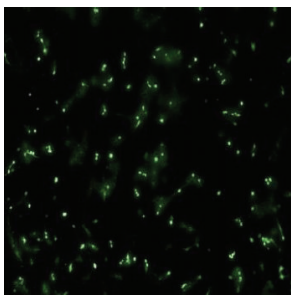

(B)

(a)

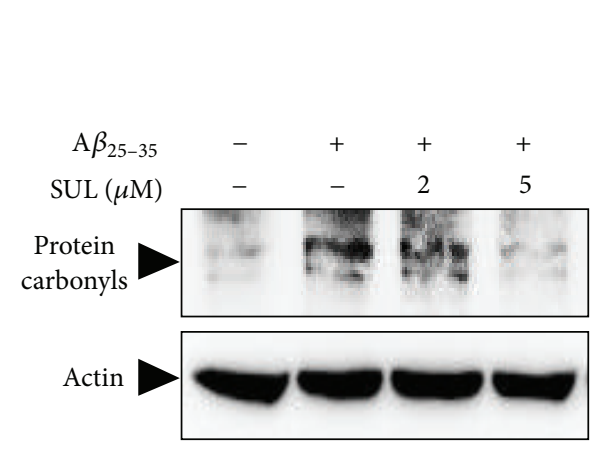

(c)

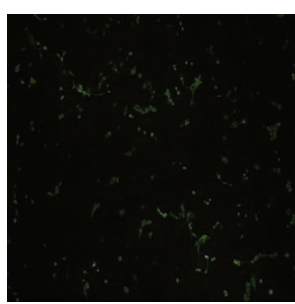

(C)

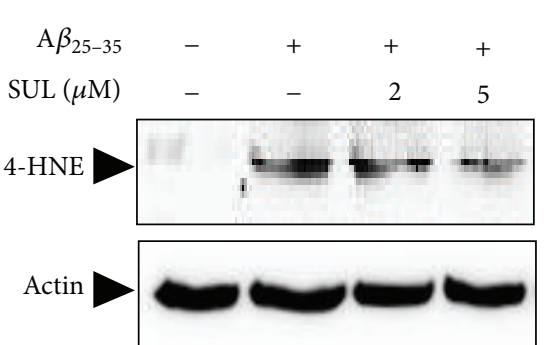

(b)

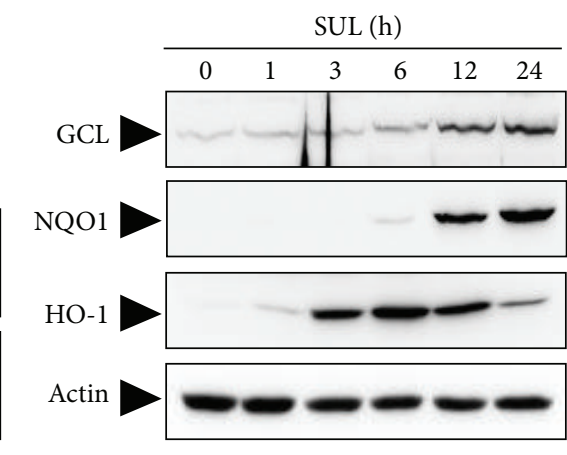

(d)

FIGURE 4: Inhibitory effect of SUL on the A $\beta_{25-35}$-induced intracellular accumulation of ROS and oxidative stress. (a) SH-SY5Y cells were treated with $15 \mu \mathrm{M} \mathrm{A} \beta_{25-35}$ for $6 \mathrm{~h}$ with or without SUL pretreatment for $30 \mathrm{~min}$. Intracellular ROS levels were monitored by using DCF-DA fluorescence dye. (A) Vehicle-treated control; (B) $\mathrm{A} \beta_{25-35}$ alone $(15 \mu \mathrm{M})$; (C) $\mathrm{A} \beta_{25-35}(15 \mu \mathrm{M})+\mathrm{SUL}(5 \mu \mathrm{M})$. ((b)-(c)) SH-SY5Y cells were exposed to $15 \mu \mathrm{M} \mathrm{A} \beta_{25-35}$ in the presence or absence of SUL $(2 \mu \mathrm{M}$ and $5 \mu \mathrm{M})$ for $24 \mathrm{~h}$. Molecular markers for oxidative damages such as lipid peroxidation (b) and protein oxidation (c) were determined by western blot analysis and protein carbonyl assay as described in Section 2. (d) The protein expression of antioxidant enzymes for example GCS, NQO-1, and HO-1 was evaluated by western blotting using their specific antibodies. Actin levels were assessed to confirm the equal amount of protein loaded.

transfection. These results suggest a critical role of Nrf2 in SUL-mediated protection against $\mathrm{A} \beta_{25-35}$-induced apoptotic cell death.

\section{Discussion}

In this study, we have examined the protective effect and molecular mechanism of SUL against A $\beta$-induced oxidative and apoptotic cell death. The results from the MTT assay and apoptotic analysis (TUNEL) provided a direct evidence demonstrating that SUL could protect SH-SY5Y cells from $\mathrm{A} \beta_{25-35}$-induced toxicity through increasing cell viability as well as inhibiting the apoptotic cell death. We also have assessed the effect of SUL on the $\mathrm{A} \beta_{25-35}$-induced proapoptotic signals such as activation of JNK and increased ratio of Bax to Bcl-2. Pretreatment of SUL elevated the antiapoptotic Bcl-2 protein levels, decreased the pro-apoptotic Bax protein expression, and attenuated JNK activation via inhibition of its phosphorylation.

It has been reported that $\mathrm{A} \beta_{25-35}$-induced cytotoxicity was mediated by oxidative stress. The excessive production of ROS by $A \beta_{25-35}$ and exhaustion of the endogenous antioxidant defense system including GSH, catalase, superoxide dismutase, and glutathione metabolizing enzymes can cause oxidative damages to critical cellular macromolecules, mitochondrial dysfunction, and altered cellular signal transduction cascades. In the present study, $\mathrm{A} \beta_{25-35}$ treatment led to intracellular accumulation of ROS in SH-SY5Y cells, which was effectively inhibited by pretreatment with SUL. Moreover, SUL could alleviate $\mathrm{A} \beta_{25-35}$-induced oxidative damages including formation of 4 -HNE and protein carbonyls through decreasing ROS production. Dissipation of MMP reflects the opening of the mitochondrial permeability transition pore due to the ROS release from mitochondria [19]. In this study, during the apoptotic cell death induced by $\mathrm{A} \beta_{25-35}$, MMP generated by the gradient of ion concentrations between two sides of the mitochondrial membrane was decreased, whereas SUL pretreatment restored the dissipation of MMP. In accordance with our finding, it has been reported that SUL increases the resistance of liver mitochondria to redox-regulated permeability transition pore opening and elevates expression of antioxidant proteins involved in mitochondrial defense against oxidative stress [20].

As the accumulation of ROS can trigger imbalance of redox state, neuronal cells have a set of antioxidant defense enzymes that maintain homeostasis between them. Therefore, one way to render neuronal cells more resistant to $\mathrm{A} \beta$-induced oxidative cell death is to potentiate the endogenous antioxidant defense system, for instance, to upregulate an array of antioxidant enzymes. In the present 


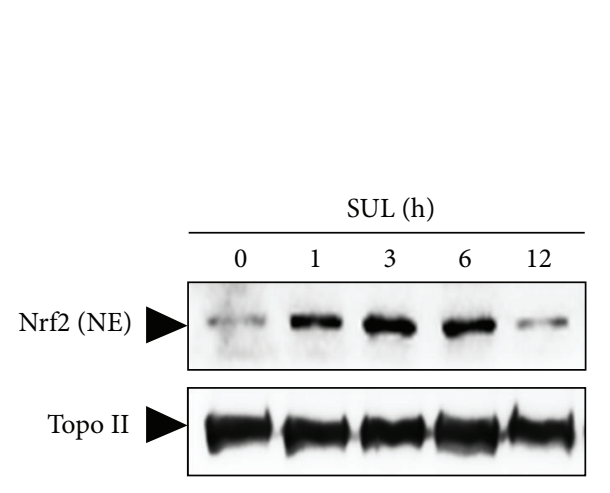

(a)

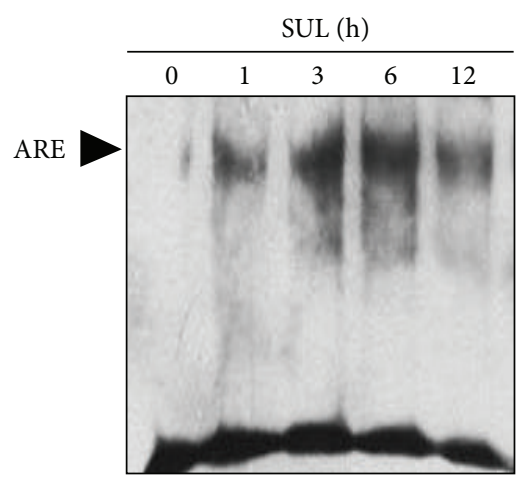

(b)

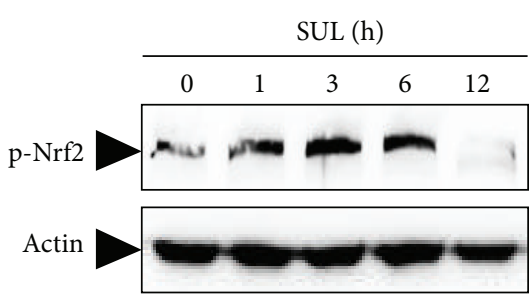

(c)

FIGURE 5: SUL-induced activation of Nrf2 in SH-SY5Y cells. Cells were incubated with SUL (5 $\mu \mathrm{M})$ for indicated times and nuclear as well as total protein sample extracts were prepared. (a) Nuclear translocation of Nrf2 was monitored by western blotting of nuclear extracts by probing with anti-Nrf2 specific antibody. (b) Nrf2-ARE binding activity was measured by EMSA according to the manufacturer's instruction using biotin-labeled oligonucleotide specific for Nrf2. (c) Phosphorylation of Nrf2 was assessed by western blot analysis with anti-phosphoNrf2 (Ser40) antibody. The levels of Topo II (a) and actin (c) were examined to ensure equal amount of nuclear and total protein as loading controls, respectively.

study, treatment of SUL elevated the protein expression of antioxidant enzymes such as GCL, NQO-1, and HO-1. GCL is a rate-limiting enzyme for biosynthesis of GSH which is a representative endogenous antioxidant molecule and plays an important role in cellular defense against oxidative stress [21]. Because homeostasis of GSH and GSH-dependent enzymes are considered to be key determinants of antioxidant protection, dysregulation of GSH-related antioxidant network might bring about the initiation and progression of neurodegenerative diseases where oxidative stress is one of critical causes [22].

NQO-1 is a cytosolic flavoprotein that catalyzes the twoelectron reduction of quinones to the redox-stable hydroquinones, preventing their redox cycling and eventually generating the ROS [23]. Increasing evidence supports the role of NQO-1 as a safety valve to sequester ROS and prevent severe oxidative damages in various neuronal disorders including $\mathrm{AD}[23,24]$. HO-1, known as heat shock protein 32 , plays a crucial role in endogenous defense against oxidative stimuliinduced brain injuries by decomposing toxic heme into carbon monoxide, iron, and biliverdin [25]. Biliverdin is subsequently converted into bilirubin through the action of biliverdin reductase and these two molecules serve as potent radical scavengers protecting cells from oxidative damages. The pharmacological up-regulation of HO-1 expression in brain regions showed promising therapeutic effects in the models of neurodegenerative diseases and brain infections [26].

To further elucidate the upstream regulators for the induction of endogenous antioxidant defense enzymes against oxidative stress, we have focused on the Nrf2-ARE signaling pathway. Recently, abundant evidence suggests the protective functions of Nrf2 and Nrf2-regulated gene products in diverse neuronal disorders $[27,28]$. Considering that Nrf2 mediates general antioxidant responses, Nrf2 could be a potential therapeutic target for neurodegenerative diseases, where cells are suffering from chronic state of oxidative stress. Under normal quiescent state, $\mathrm{Nrf} 2$ is sequestered in the cytoplasm by a cytoskeletal associated specific negative regulator, Kelch-like ECH associating protein 1 (Keap1). Upon exposure to ROS or xenobiotics, Nrf2 is liberated from Keap1, translocates from the cytosol to the nucleus, heterodimerizes with accessory proteins such as small Maf protein family, and sequentially binds to antioxidant response element (ARE) promoter region. The binding of Nrf2 to ARE induces the production of diverse antioxidant enzyme and phase II detoxifying genes such as GCL, glutathione-Stransferase (GST), UDP-glycosyltransferases (UGTs), HO-1, and NQO1, which protect cells against oxidative stress as well as a wide range of other toxins $[27,28]$.

In the present study, the cytoprotective effect of SUL against $A \beta_{25-35}$-induced oxidative damage and cell death seemed to be mediated by up-regulation of antioxidant enzymes through Nrf2 activation. SUL has been considered as an indirect antioxidant because of its ability solely to induce many cytoprotective antioxidant enzymes through the Nrf2-ARE pathway [29]. Induction of the Nrf2-ARE pathway by SUL has been reported to prevent cytotoxicity caused by oxygen and glucose deprivation $[15,30], 6-\mathrm{OHDA}$ $[16,31]$, superoxide [17], $\mathrm{H}_{2} \mathrm{O}_{2}$ and glutamate [18], 5-Scysteinyl-dopamine [32], or $\mathrm{A} \beta_{1-42}$ [33] in neuronal cell lines as well as primary cultures. Furthermore, activation of the Nrf2-ARE pathway is able to protect against brain injuries in the animal models of neurodegenerative diseases $[34,35]$, spinal cord injury [36-38], focal cerebral ischemia [39], hypoxia-ischemic injury [14], traumatic brain injury [40], subarachnoid [41] or intracerebral hemorrhage [42], or epilepsy [43]. According to in vivo studies, strategies to potentiate Nrf2-ARE pathway by SUL were proved to be useful in improving memory impairment and cognitive dysfunction caused by traumatic brain injury [44] or A $\beta$ [34]. Conversely, Nrf2 KO mice models of neurological disorders including Parkinson's disease [35], spinal cord injury [37], traumatic brain injury [40], intracerebral hemorrhage [42], 


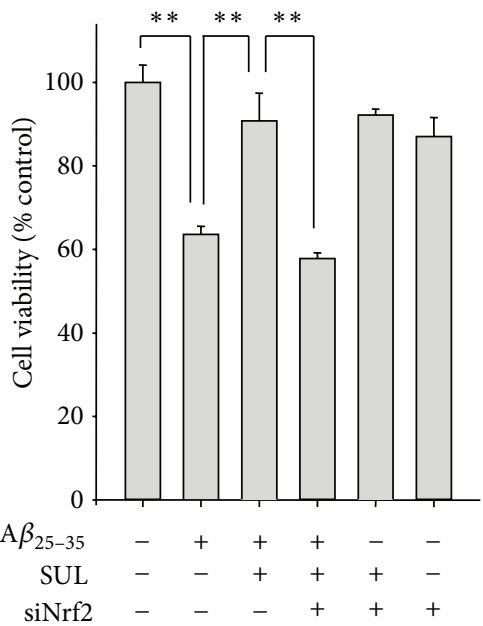

(a)

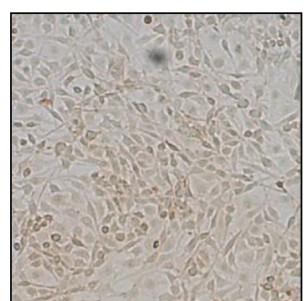

(A)

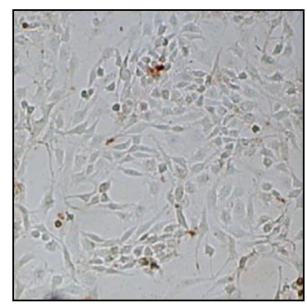

(C)

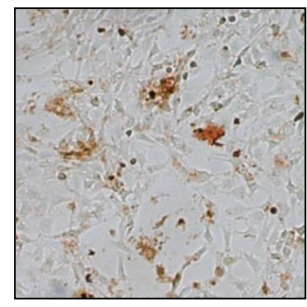

(B)

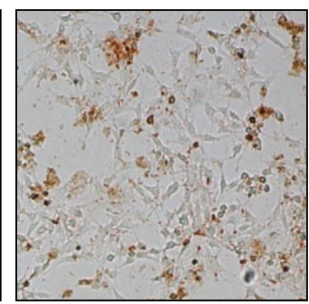

(D)

(b)

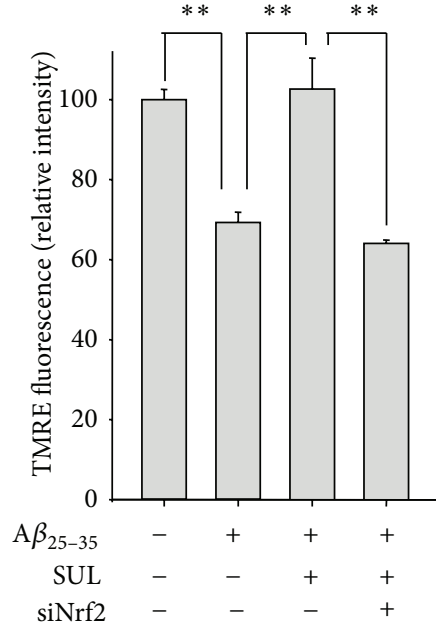

(c)

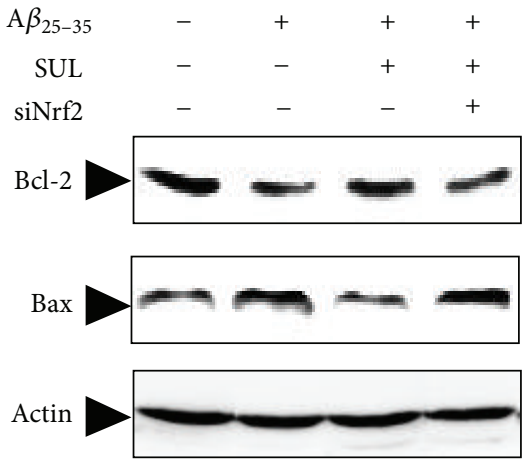

(d)

FIGURE 6: Effect of Nrf2 gene knock-down on SUL-mediated protection against A $\beta_{25-35}$-induced apoptotic cell death. SH-SY5Y cells were transiently transfected with siRNA of Nrf2 according to the protocol provided by manufacturer and then exposed to $\mathrm{A} \beta_{25-35}$ (15 $\left.\mu \mathrm{M}\right)$ in the presence or absence of SUL $(5 \mu \mathrm{M})$ for $24 \mathrm{~h}$. (a) MTT assay was performed to measure cell viability. Data are represented as mean \pm S.D. $(n=3) .{ }^{* *} P<0.01$, significantly different between groups. (b) TUNEL staining was conducted to verify DNA fragmentation in situ. (A) Vehicle-treated control; (B) $\mathrm{A} \beta_{25-35}$ alone $(15 \mu \mathrm{M}) ;$; (C) $\mathrm{A} \beta_{25-35}(15 \mu \mathrm{M})+\mathrm{SUL}(5 \mu \mathrm{M}) ;$ (D) $\mathrm{A} \beta_{25-35}(15 \mu \mathrm{M})+\mathrm{SUL}(5 \mu \mathrm{M})+\mathrm{Nrf2}$-siRNA. (c) TMRE staining was performed to compare MMP. Data are represented as mean \pm S.D. $(n=3) .{ }^{* *} P<0.01$, significantly different between groups. (d) Protein expression of Bcl-2 and Bax was determined by western blot analysis using specific antibodies. Actin levels were examined to ensure equal amount of protein loading.

and epilepsy [43] exhibited increased susceptibility to neurological oxidative damages but did not maintain any benefits from the protective effects of SUL. In our experiment, the protective effect of SUL against $\mathrm{A} \beta_{25-35}$-caused apoptotic cell death was abolished by down-regulation of Nrf2 gene by transient transfection with Nrf2-siRNA.

Although the molecular milieu of SUL-induced Nrf2 activation in SH-SY5Y cells has not been elucidated, two possible mechanisms for the activation of Nrf2-ARE pathway by SUL have been proposed in other types of cells. One is structural change of Keapl due to the modification of specific cysteine residues by binding of SUL $[29,45]$. The other is the phosphorylation of Nrf2 at Ser- 40 residue by mitogen-activated protein kinases [46], protein kinase C [46], and phosphatidylinositol 3-kinase/Akt activated by SUL $[31,47,48]$. Nrf2 phosphorylation by aforementioned kinases triggers the release of Nrf2 from inhibitory Keapl, thereby facilitating the Nrf2 translocation to nucleus. However, phosphorylation of Nrf2 at Tyr-568 residue by GSK$3 \beta$ can promote its nuclear exclusion or proteolysis [46, 49]. Nevertheless, the molecular signaling pathways activating Nrf2 appears to be pleiotropic and dependent on cell types as well as stimuli.

\section{Conclusions}

In conclusion, a phytochemical SUL attenuates $A \beta_{25-35^{-}}$ induced oxidative stress and pro-apoptotic signals such as activation of JNK, an increase in pro-apoptotic Bax, and a decrease in anti-apoptotic Bcl-2, thereby inhibiting apoptotic neuronal cell death in SH-SY5Y cells. Moreover, SUL induced the activation of Nrf2-ARE signaling pathway, which 


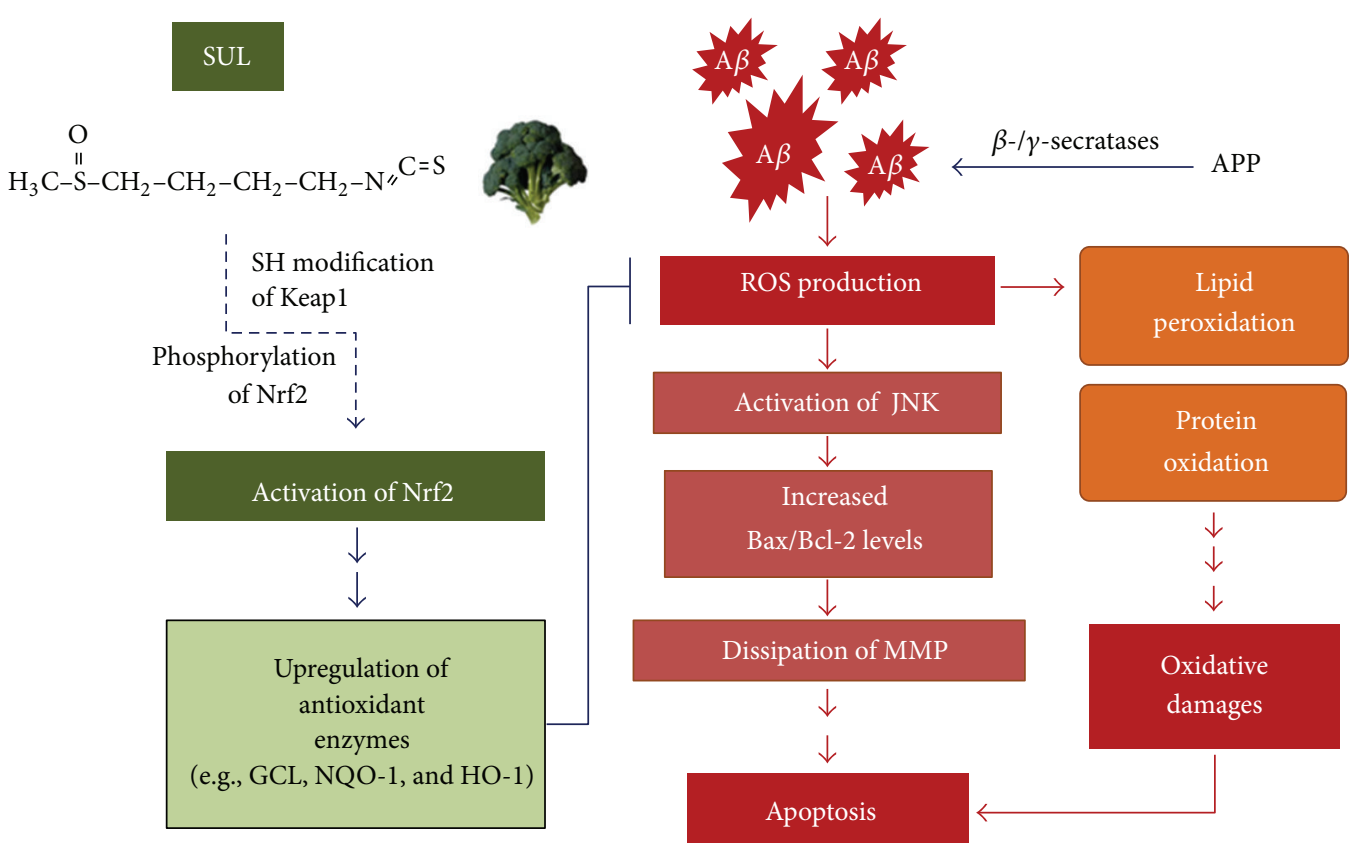

FIGURE 7: Schematic diagram that describes neuroprotective effects of SUL against A $\beta$-induced oxidative cell death in AD. SUL attenuates $\mathrm{A} \beta$-induced oxidative damages, pro-apoptotic signals, and apoptotic cell death through the activation of Nrf2-ARE signaling pathway, which consequently fortify Nrf2-dependent antioxidant defense capacity.

consequently results in up-regulation of Nrf2-dependent antioxidant capacity, leading to reduction in the $\mathrm{A} \beta_{25-35^{-}}$ induced oxidative damages (Figure 7 ). Taken together, the results in the present study suggest pharmacologic activation of the Nrf2 signaling pathway by SUL might be a practical preventative and therapeutic strategy for AD patients. However, further studies are required to obtain more insights into the molecular mechanisms of SUL-induced Nrf2 activation and clinical application of SUL.

\section{Conflict of Interests}

The authors declare that they have no conflict of interests.

\section{Authors' Contribution}

Chan Lee and Gyu Hwan Park contributed equally to this work.

\section{Acknowledgments}

This work was supported by the National Research Foundation of Korea (NRF) grant funded by the Ministry of Education, Science and Technology, Korea government (nos. 2009-0067980 and 2010-0004959).

\section{References}

[1] D. M. Barten and C. F. Albright, "Therapeutic strategies for Alzheimer's disease," Molecular Neurobiology, vol. 37, no. 2-3, pp. 171-186, 2008.
[2] M. P. Mattson, "Pathways towards and away from Alzheimer's disease," Nature, vol. 430, no. 7000, pp. 631-639, 2004.

[3] M. W. Marlatt, P. J. Lucassen, G. Perry, M. A. Smith, and X. Zhu, "Alzheimer's disease: cerebrovascular dysfunction, oxidative stress, and advanced clinical therapies," Journal of Alzheimer's Disease, vol. 15, no. 2, pp. 199-210, 2008.

[4] R. Sultana, M. Perluigi, and D. A. Butterfield, "Oxidatively modified proteins in Alzheimer's disease (AD), mild cognitive impairment and animal models of AD: role of Abeta in pathogenesis," Acta Neuropathologica, vol. 118, no. 1, pp. 131-150, 2009.

[5] D. A. Butterfield, J. Drake, C. Pocernich, and A. Castegna, "Evidence of oxidative damage in Alzheimer's disease brain: central role for amyloid $\beta$-peptide," Trends in Molecular Medicine, vol. 7, no. 12, pp. 548-554, 2001.

[6] A. Gella and N. Durany, "Oxidative stress in Alzheimer disease," Cell Adhesion and Migration, vol. 3, no. 1, pp. 88-93, 2009.

[7] S.-Y. Park, "Potential therapeutic agents against Alzheimer's disease from natural sources," Archives of Pharmacal Research, vol. 33, no. 10, pp. 1589-1609, 2010.

[8] P. Williams, A. Sorribas, and M.-J. R. Howes, "Natural products as a source of Alzheimer's drug leads," Natural Product Reports, vol. 28, no. 1, pp. 48-77, 2011.

[9] K. L. Cheung and A.-N. Kong, "Molecular targets of dietary phenethyl isothiocyanate and sulforaphane for cancer chemoprevention," AAPS Journal, vol. 12, no. 1, pp. 87-97, 2010.

[10] B. M. Kaminski, D. Steinhilber, J. M. Stein, and S. Ulrich, "Phytochemicals resveratrol and sulforaphane as potential agents for enhancing the anti-tumor activities of conventional cancer therapies," Current Pharmaceutical Biotechnology, vol. 13, no. 1, pp. 137-146, 2012.

[11] C. E. Guerrero-Beltrán, M. Calderón-Oliver, J. Pedraza-Chaverri, and Y. I. Chirino, "Protective effect of sulforaphane against 
oxidative stress: recent advances," Experimental and Toxicologic Pathology, vol. 64, no. 5, pp. 503-508, 2012.

[12] N. A. Kelsey, H. M. Wilkins, and D. A. Linseman, "Nutraceutical antioxidants as novel neuroprotective agents," Molecules, vol. 15, no. 11, pp. 7792-7814, 2010.

[13] N. G. Innamorato, A. I. Rojo, Á. J. García-Yagüe, M. Yamamoto, M. L. De Ceballos, and A. Cuadrado, "The transcription factor nrf2 is a therapeutic target against brain inflammation," Journal of Immunology, vol. 181, no. 1, pp. 680-689, 2008.

[14] Z. Ping, W. Liu, Z. Kang et al., "Sulforaphane protects brains against hypoxic-ischemic injury through induction of Nrf2dependent phase 2 enzyme," Brain Research, vol. 1343, pp. 178185, 2010.

[15] C. A. Danilov, K. Chandrasekaran, J. Racz, L. Soane, C. Zielke, and G. Fiskum, "Sulforaphane protects astrocytes against oxidative stress and delayed death caused by oxygen and glucose deprivation," GLIA, vol. 57, no. 6, pp. 645-656, 2009.

[16] A. Siebert, V. Desai, K. Chandrasekaran, G. Fiskum, and M. S. Jafri, "Nrf2 activators provide neuroprotection against 6-hydroxydopamine toxicity in rat organotypic nigrostriatal cocultures," Journal of Neuroscience Research, vol. 87, no. 7, pp. 1659-1669, 2009.

[17] P. Bergström, H. C. Andersson, Y. Gao et al., "Repeated transient sulforaphane stimulation in astrocytes leads to prolonged Nrf2mediated gene expression and protection from superoxideinduced damage," Neuropharmacology, vol. 60, no. 2-3, pp. 343353, 2011.

[18] A. D. Kraft, D. A. Johnson, and J. A. Johnson, "Nuclear factor E2-related factor 2-dependent antioxidant response element activation by tert-butylhydroquinone and sulforaphane occurring preferentially in astrocytes conditions neurons against oxidative insult," Journal of Neuroscience, vol. 24, no. 5, pp. 11011112, 2004.

[19] B. Mignotte and J.-L. Vayssiere, "Mitochondria and apoptosis," European Journal of Biochemistry, vol. 252, no. 1, pp. 1-15, 1998.

[20] T. Greco, J. Shafer, and G. Fiskum, "Sulforaphane inhibits mitochondrial permeability transition and oxidative stress," Free Radical Biology and Medicine, vol. 51, no. 12, pp. 2164-2171, 2011.

[21] K. Aoyama, M. Watabe, and T. Nakaki, "Regulation of neuronal glutathione synthesis," Journal of Pharmacological Sciences, vol. 108, no. 3, pp. 227-238, 2008.

[22] W. M. Johnson, A. L. Wilson-Delfosse, and J. J. Mieyal, "Dysregulation of glutathione homeostasis in neurodegenerative diseases," Nutrients, vol. 4, no. 10, pp. 1399-1440, 2012.

[23] A. K. Raina, D. J. Templeton, J. C. Deak, G. Perry, and M. A. Smith, "Quinone reductase (NQO1), a sensitive redox indicator, is increased in Alzheimer's disease," Redox Report, vol. 4, no. 1-2, pp. 23-27, 1999.

[24] Y. Wang, K. Santa-Cruz, C. Decarli, and J. A. Johnson, "NAD(P)H:quinone oxidoreductase activity is increased in hippocampal pyramidal neurons of patients with Alzheimer's disease," Neurobiology of Aging, vol. 21, no. 4, pp. 525-531, 2000.

[25] A. Jazwa and A. Cuadrado, "Targeting heme oxygenase-1 for neuroprotection and neuroinflammation in neurodegenerative diseases," Current Drug Targets, vol. 11, no. 12, pp. 1517-1531, 2010.

[26] A. Cuadrado and A. I. Rojo, "Heme oxygenase-1 as a therapeutic target in neurodegenerative diseases and brain infections," Current Pharmaceutical Design, vol. 14, no. 5, pp. 429-442, 2008.
[27] G. Joshi and J. A. Johnson, “The Nrf2-ARE pathway: a valuable therapeutic target for the treatment of neurodegenerative diseases," Recent Patents on CNS Drug Discovery, vol. 7, no. 3, pp. 218-229, 2012.

[28] F. L. van Muiswinkel and H. B. Kuiperij, "The Nrf2-ARE signalling pathway: promising drug target to combat oxidative stress in neurodegenerative disorders," Current Drug Targets, vol. 4, no. 3, pp. 267-281, 2005.

[29] A. T. Dinkova-Kostova and P. Talalay, "Direct and indirect antioxidant properties of inducers of cytoprotective proteins," Molecular Nutrition and Food Research, vol. 52, supplement 1, pp. S128-S138, 2008.

[30] L. Soane, W. Li Dai, G. Fiskum, and L. L. Bambrick, "Sulforaphane protects immature hippocampal neurons against death caused by exposure to hemin or to oxygen and glucose deprivation," Journal of Neuroscience Research, vol. 88, no. 6, pp. 1355-1363, 2010.

[31] C. Deng, R. Tao, S.-Z. Yu, and H. Jin, "Sulforaphane protects against 6-hydroxydopamine-induced cytotoxicity by increasing expression of heme oxygenase-1 in a PI3K/Akt-dependent manner," Molecular Medicine Reports, vol. 5, no. 3, pp. 847-851, 2012.

[32] D. Vauzour, M. Buonfiglio, G. Corona et al., "Sulforaphane protects cortical neurons against 5-S-cysteinyl-dopamine-induced toxicity through the activation of ERK1/2, NrF-2 and the upregulation of detoxification enzymes," Molecular Nutrition and Food Research, vol. 54, no. 4, pp. 532-542, 2010.

[33] H.-M. Park, J.-A. Kim, and M.-K. Kwak, "Protection against amyloid beta cytotoxicity by sulforaphane: role of the proteasome," Archives of Pharmacal Research, vol. 32, no. 1, pp. 109-115, 2009.

[34] H. V. Kim, H. Y. Kim, H. Y. Ehrlich, S. Y. Choi, D. J. Kim, and Y. Kim, "Amelioration of Alzheimer's disease by neuroprotective effect of sulforaphane in animal model," Amyloid, vol. 20, no. 1, pp. 7-12, 2012.

[35] A. Jazwa, A. I. Rojo, N. G. Innamorato, M. Hesse, J. FernándezRuiz, and A. Cuadrado, "Pharmacological targeting of the transcription factor NRf2 at the basal ganglia provides disease modifying therapy for experimental parkinsonism," Antioxidants and Redox Signaling, vol. 14, no. 12, pp. 2347-2360, 2011.

[36] A. Jazwa, A. I. Rojo, N. G. Innamorato, M. Hesse, J. FernandezRuiz, and A. Cuadrado, "Pharmacological targeting of the transcription factor $\mathrm{Nrf} 2$ at the basal ganglia provides disease modifying therapy for experimental parkinsonism," Antioxidants \& Redox Signaling, vol. 14, no. 12, pp. 2347-2360, 2011.

[37] L. Mao, H. Wang, X. Wang, H. Liao, and X. Zhao, “Transcription factor Nrf2 protects the spinal cord from inflammation produced by spinal cord injury," Journal of Surgical Research, vol. 170, no. 1, pp. e105-e115, 2011.

[38] X. Wang, J. P. d. R. Vaccari, H. Wang et al., "Activation of the nuclear factor E2-related factor 2/antioxidant response element pathway is neuroprotective after spinal cord injury," Journal of Neurotrauma, vol. 29, no. 5, pp. 936-945, 2012.

[39] J. Zhao, N. Kobori, J. Aronowski, and P. K. Dash, "Sulforaphane reduces infarct volume following focal cerebral ischemia in rodents," Neuroscience Letters, vol. 393, no. 2-3, pp. 108-112, 2006.

[40] Y. Hong, W. Yan, S. Chen, C. R. Sun, and J. M. Zhang, "The role of Nrf2 signaling in the regulation of antioxidants and detoxifying enzymes after traumatic brain injury in rats and mice," Acta Pharmacologica Sinica, vol. 31, no. 11, pp. 1421-1430, 2010. 
[41] G. Chen, Q. Fang, J. Zhang, D. Zhou, and Z. Wang, "Role of the Nrf2-ARE pathway in early brain injury after experimental subarachnoid hemorrhage," Journal of Neuroscience Research, vol. 89, no. 4, pp. 515-523, 2011.

[42] X. Zhao, G. Sun, J. Zhang et al., "Transcription factor Nrf2 protects the brain from damage produced by intracerebral hemorrhage," Stroke, vol. 38, no. 12, pp. 3280-3286, 2007.

[43] A. I. Rojo, P. Rada, J. Egea, A. O. Rosa, M. G. López, and A. Cuadrado, "Functional interference between glycogen synthase kinase- 3 beta and the transcription factor Nrf2 in protection against kainate-induced hippocampal celldeath," Molecular and Cellular Neuroscience, vol. 39, no. 1, pp. 125-132, 2008.

[44] P. K. Dash, J. Zhao, S. A. Orsi, M. Zhang, and A. N. Moore, "Sulforaphane improves cognitive function administered following traumatic brain injury," Neuroscience Letters, vol. 460, no. 2, pp. 103-107, 2009.

[45] C. Hu, A. L. Eggler, A. D. Mesecar, and R. B. Van Breemen, "Modification of Keap1 cysteine residues by sulforaphane," Chemical Research in Toxicology, vol. 24, no. 4, pp. 515-521, 2011.

[46] Y.-S. Keum, "Regulation of the Keap1/Nrf2 system by chemopreventive sulforaphane: implications of posttranslational modifications," Annals of the New York Academy of Sciences, vol. 1229, no. 1, pp. 184-189, 2011.

[47] E. Leoncini, M. Malaguti, C. Angeloni, E. Motori, D. Fabbri, and S. Hrelia, "Cruciferous vegetable phytochemical sulforaphane affects phase II enzyme expression and activity in rat cardiomyocytes through modulation of Akt signaling pathway," Journal of Food Science, vol. 76, no. 7, pp. H175-H181, 2011.

[48] L. Wang, Y. Chen, P. Sternberg, and J. Cai, "Essential roles of the PI3 kinase/Akt pathway in regulating Nrf2-dependent antioxidant functions in the RPE," Investigative Ophthalmology and Visual Science, vol. 49, no. 4, pp. 1671-1678, 2008.

[49] M. Salazar, A. I. Rojo, D. Velasco, R. M. De Sagarra, and A. Cuadrado, "Glycogen synthase kinase- $3 \beta$ inhibits the xenobiotic and antioxidant cell response by direct phosphorylation and nuclear exclusion of the transcription factor Nrf2," Journal of Biological Chemistry, vol. 281, no. 21, pp. 14841-14851, 2006. 


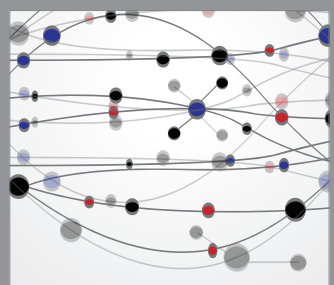

The Scientific World Journal
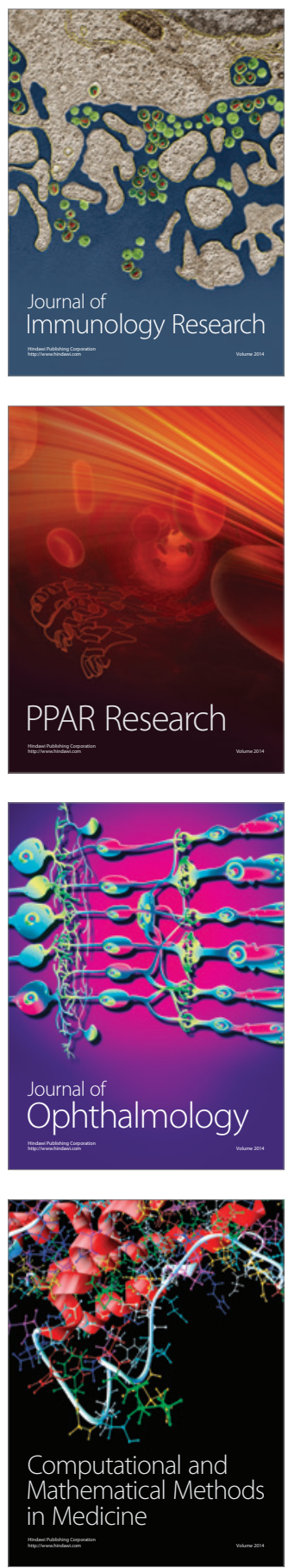

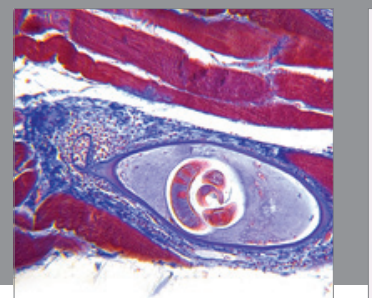

Gastroenterology

Research and Practice
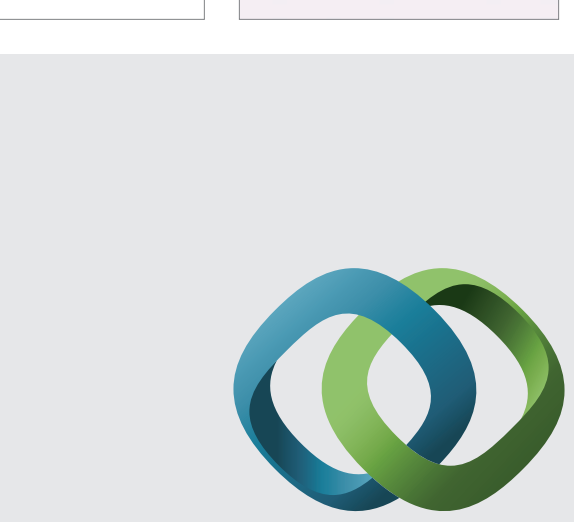

\section{Hindawi}

Submit your manuscripts at

http://www.hindawi.com
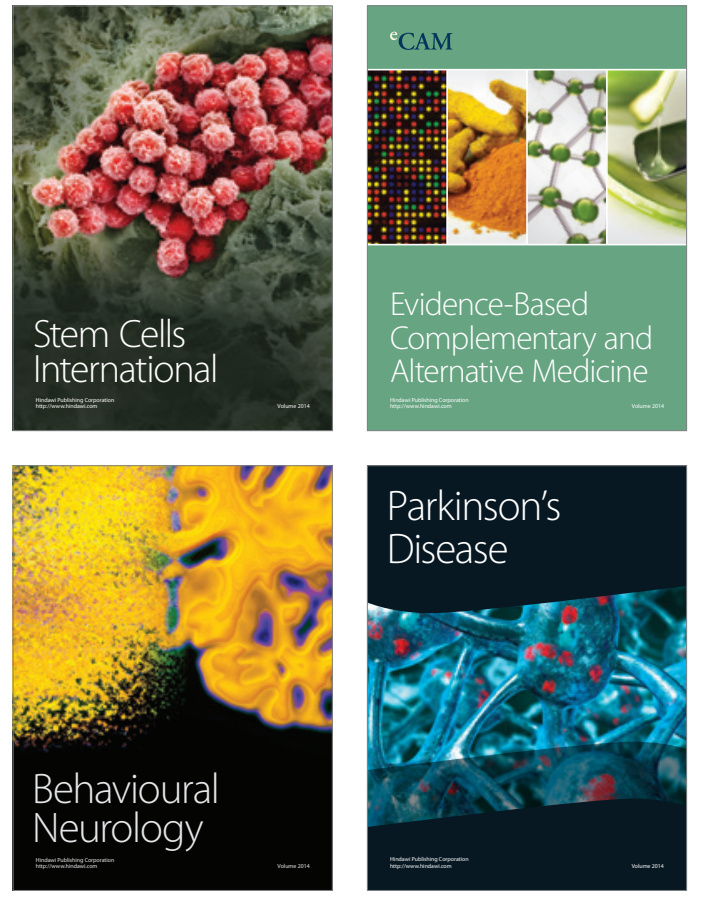
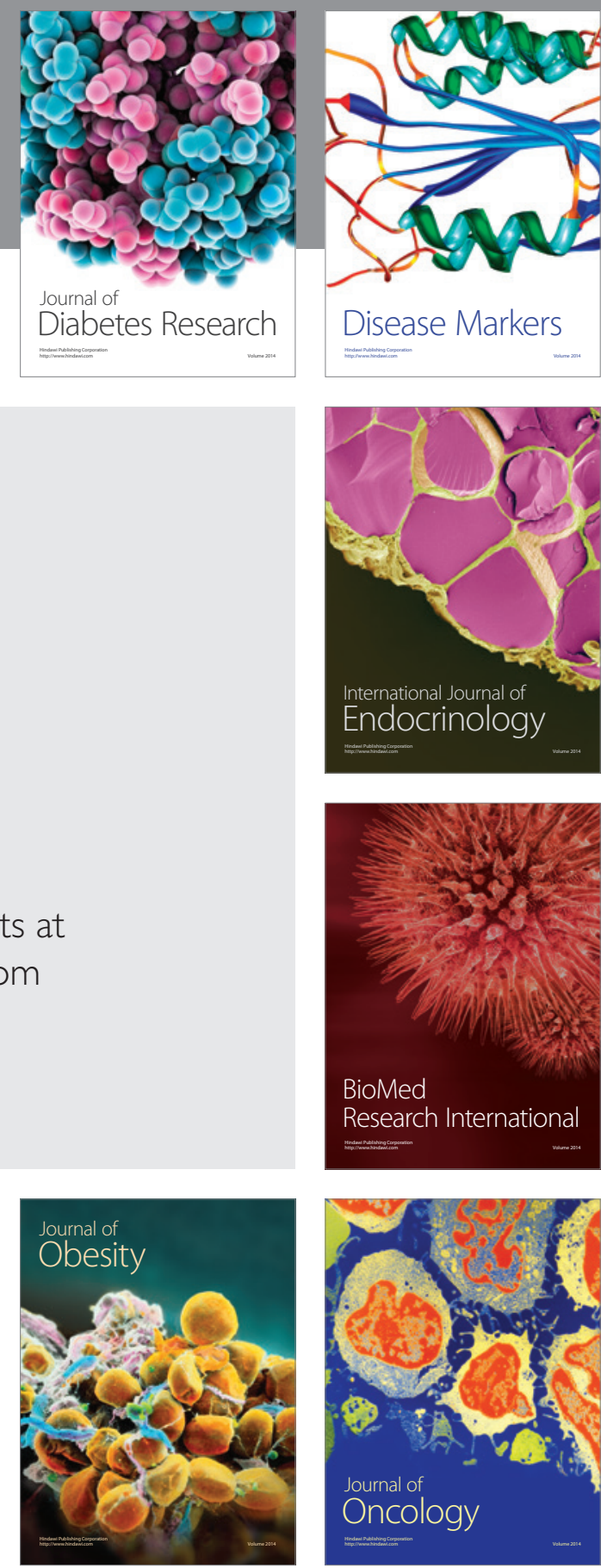

Disease Markers
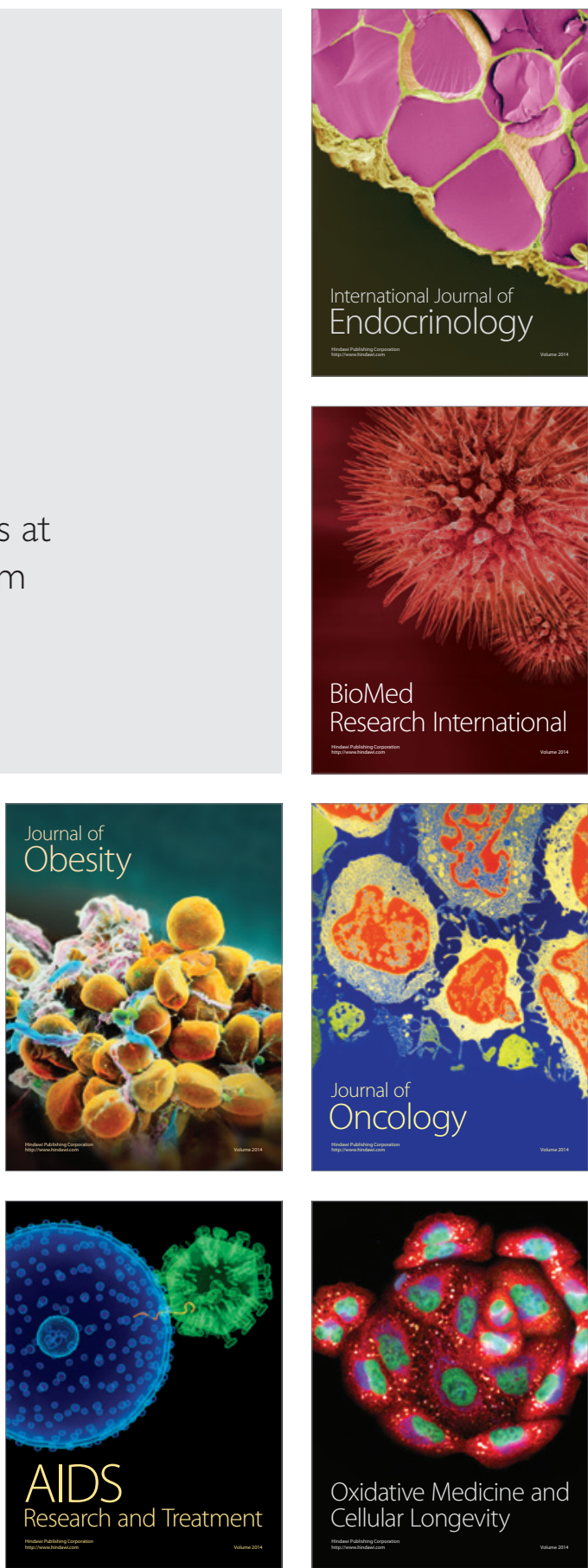